\title{
GRANITOS E PATRIMÓNIO CULTURAL CONSTRUÍDO. DOS PROBLEMAS ÀS SOLUÇÕES
}

\author{
José Delgado Rodrigues ${ }^{1}$, Dória Costa ${ }^{2}$ \\ 1 - Geólogo, Investigador Coordenado do LNEC (Ap.), Lisboa, Portugal; 2 - Geóloga, Investigadora Auxiliar do LNEC \\ delgado@Inec.pt
}

\begin{abstract}
Resumo: O artigo faz um enquadramento da utilização das rochas graníticas na construção de património cultural, em especial na vertente das obras de arquitectura, e analisa algumas especificidades destes materiais que os tornam singulares em termos do seu comportamento em obra. Abordam-se os aspectos relativos ao seu carácter poliminerálico e às formas mais características de deterioração. Enumeram-se e discutem-se aspectos relevantes ligados à conservação de superfícies deterioradas e apresentam-se alguns casos típicos que ilustram os problemas e algumas opções de conservação em imóveis classificados em Portugal.
\end{abstract}

Palavras Chave: granito; património construído; deterioração; conservação

Abstract: GRANITES AND BUILT CULTURAL HERITAGE. FROM PROBLEMS TO SOLUTIONS. The article presents a brief review on the use of granitic rocks in built cultural heritage, and discusses some properties that make them unique in terms of their performance as construction materials. It addresses aspects related to its polymineralic composition and analyzes some of their more characteristics deterioration forms. A few relevant aspects related to the conservation of damaged surfaces are identified and discussed and some typical cases are presented to illustrate the problems and the conservation options adopted in some Portuguese case studies.

Keywords: granite; built heritage; deterioration; conservation

\section{INTRODUÇÃO}

Utilizamos a designação de granitos ou de rochas graníticas para identificar um vasto leque de rochas ígneas, de composições variadas, portanto sem aparente razoabilidade petrográfica, mas com propriedades e comportamentos em obra suficientemente parecidos para poderem ser encarados sob uma perspectiva comum e serem portanto designados desta forma muito abrangente.

No âmbito dos estudos ligados ao património construído, importa saber utilizar os conhecimentos petrográficos especializados e perceber o que significam as variações dentro dos grupos ou famílias, mas importa também saber identificar e valorar os traços comuns a diferentes variedades petrográficas, o seu significado em termos de comportamento, e elaborar modelos interpretativos que permitam aos não especialistas poder lidar com este vastíssimo grupo de rochas de enorme valor como origem de materiais de construção, hoje, como no passado.

$\mathrm{Na}$ classificação das rochas ígneas plutónicas elaborada pela IUGS (STRECKEISEN 1976), os granitos ocupam um campo bem definido, ao qual corresponde um teor de quartzo relevante, da ordem dos 30 a 50\%, numa massa de feldspatos alcalinos e plagioclases sódico-cálcicas. $\mathrm{Na}$ perspectiva do seu estudo como material de construção, os grupos vizinhos dos granodioritos, dioritos, sienitos e monzonitos apresentam grandes afinidades com os granitos, pelo que são habitualmente designadas em conjunto como rochas graníticas. A menos que se explicite de outra forma, usaremos o termo granitos e rochas graníticas como

doi: $10.18285 /$ geonomos.v24i2.889 sinónimos, na acepção que acaba de ser referida.

Se, do ponto de vista do significado petrológico, a presença de uma pequena percentagem de uma dada anfíbola ou piroxena, de pequenas variações nos teores relativos de $\mathrm{CaO}, \mathrm{Na}_{2} \mathrm{O}$ e $\mathrm{K}_{2} \mathrm{O}$ podem ser muito informativos, essas mesmas variações terão impacte irrelevante ou nulo quando se trata de entender o seu comportamento como material de construção. Neste âmbito, importa pois identificar as semelhanças e deduzir comportamentos comuns que possam servir de guia na interpretação do seu desempenho em obra, na compreensão dos processos de degradação que se verificam e na definição de acções que ajudem a preservar o património com elas construído.

O modelo racional para compreensão do desempenho das rochas graníticas pode (deve) começar desde logo pela sua génese, seguindo pela sua história geológica remota, passando pela sua história geológica "recente", desembocando na história que, de seguida, partilham com os seres humanos que as extraíram, utilizaram e delas usufruíram.

O presente artigo centra-se na apresentação de um modelo deste tipo, que se pretende ser simples e acessível a não-especialistas, e que se procurará ilustrar com exemplos retirados da vida real ou demonstrados em laboratório.

\section{DO MAGMA À SUPERFÍCIE, UM MUNDO DE TRANSFORMAÇÕES}

Na definição de granito (e de rochas graníticas, por extensão) diz-se que é uma rocha ígnea, plutónica, de composição ácida e prevalência dos feldspatos alcalinos e plagioclases alcalino-cálcicas sobre as plagioclases cálcicas. Os granitos são, pois, 
derivados de um magma que cristalizou a grande profundidade. Daqui resultam, desde logo, consequências muito relevantes. A cristalização ocorreu em ambiente muito estável e durante um período muito longo (da natureza de ser plutónica), pelo que toda a massa mineral é cristalina e todos os componentes puderam atingir dimensões macroscópicas. São, pois, rochas holocristalinas, granulares.

Mas se os granitos se formaram em profundidade, onde prevaleciam elevadíssimas pressões e temperaturas, a sua extracção é feita à superfície, sob condições de pressão e temperatura normais (PTN). Esta "viagem", das profundezas até à superfície, é um carácter muito marcante da evolução, pois as drásticas variações térmicas e a enorme diferença da pressão confinante induzem perturbações que determinam largamente o comportamento em obra e que importa entender.

$\mathrm{Na}$ composição das rochas graníticas salientou-se a relevante presença de quartzo e de feldspatos, e esta é, agora, a via que importa explorar. Quartzo e feldspatos têm coeficientes de dilatação térmica muito distintos, pelo que as variações térmicas que experimentaram entre o interior da crosta terrestre e a superfície induziram comportamentos muito diferenciados. Como também os respectivos módulos de deformabilidade e os comportamentos reológicos divergem, a "viagem" impõe uma forte

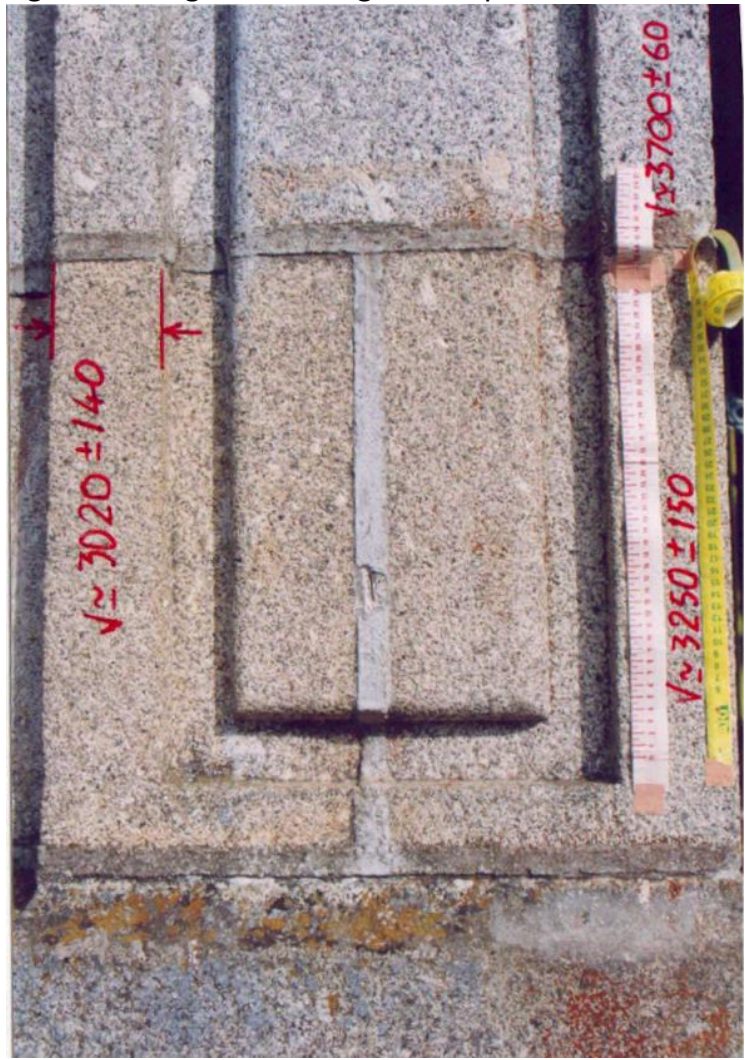

fissuração do quartzo e a deformação mais plástica dos feldspatos, resultando numa rede fissural que configura ser a propriedade mais característica das rochas graníticas como material de construção. Naturalmente, nem tudo ficou explicado, pois também a granularidade acaba por influir no resultado final, a história geotectónica pode ter desempenhado um papel mais ou menos relevante, e os fluidos que sempre as acompanharam também ajudaram na sua evolução/ transformação.

Se do ponto de vista petrológico pouco ou nada de relevante se passou, do ponto de vista da rocha como material, esta "história" é o elemento essencial para explicar o que são e como se comportam os granitos nas construções. Este é também um argumento essencial para entender que acções que se podem conceber para abordar o tratamento dos elementos que necessitam de aç̧ões de conservação.

Na Figura 1 apresentam-se os resultados de medições in situ de velocidades de propagação de ultrassons (ondas longitudinais, VL) em elementos geométricos de um monumento em granito. 0 granito é ligeiramente diferente nos dois casos, mas o que ressalta à vista são os elementos geométricos ainda perfeitamente definidos, demonstrando que as transformações ocorridas em obra não são, ainda, significativas.

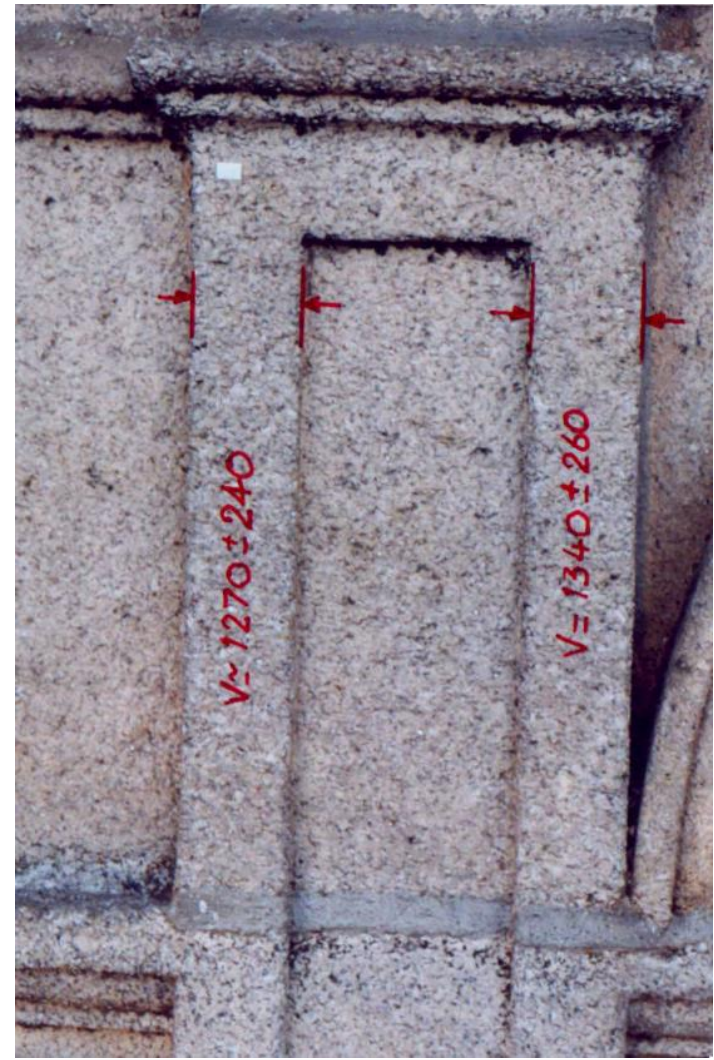

Figura 1. Velocidade de propagação de ultrassons $\left(V_{L}\right)$ em elementos geométricos de um monumento em granito (igreja do Mosteiro de Tibães). Notem-se os valores elevados, no elemento da esquerda (da ordem dos $3000 \mathrm{~m} / \mathrm{s}$ ) e baixos, no da direita (da ordem dos $1340 \mathrm{~m} / \mathrm{s}$ ). 
Se tivermos em conta que, num granito "perfeitamente" são, os valores de VL seriam algo superior a $6500 \mathrm{~m} / \mathrm{s}$, é fácil deduzir que desde a sua origem até à sua extracção esses valores terão sido reduzidos em mais de $50 \%$.

Se a grande redução sofrida pode ser explicada de forma genérica para os dois casos, a diferença significativa entre eles terá de ser explicada por outras interacções sofridas ao longo do percurso, e por diferenças de exposição na fase pré-extracção.

Entram neste elenco de factores, diferenças nos respectivos ambientes geotectónicos, por exemplo a proximidade de acidentes tectónicos, pequenas diferenças no grau de transformação química dos feldspatos devidas à hidrólise, bem como as diferenças na orografia com as consequentes diferenças na exposição aos agentes meteóricos.

Estes resultados foram obtidos num mesmo monumento e tudo leva a crer que os materiais foram extraídos em pedreiras da região, próximas entre si e ilustram a situação mais corrente em monumentos construídos em granito em regiões de clima temperado, que poderia ser traduzida pela utilização de materiais extraídos já com estados de alteração avançados, e pela potencial grande heterogeneidade que pode existir entre blocos extraídos duma mesma pedreira ou de pedreiras numa mesma região. A abordagem de qualquer estudo destinado a identificar os problemas que afectam um monumento construído em granito e que procure identificar acções de mitigação de problemas terá, obrigatoriamente, de ter estes pressupostos como elementos essenciais da sua análise.

Na Figura 2, apresentam-se mais duas situações, ainda do mesmo monumento, onde se observa uma forte desagregação, com perdas de massa já muito significativas, mostrando que também os granitos podem apresentar taxas de deterioração muito elevadas, sinal de que alguns blocos utilizados na construção continham vulnerabilidades muito significativas e não eram do típico granito, muito resistente e durável.

Estes casos documentam dois tipos de alteração muito frequente nas rochas graníticas e que se explicita para melhor compreensão. Os blocos da Figura 1 apresentam todos as suas arestas ainda muito bem definidas, podendo-se admitir que não terão sofrido grandes transformações desde que foram ali colocadas. Nesta perspectiva, os baixos valores de VL significam que os blocos estavam já alterados na altura da construção. A esta modificação das características físicas chamamos "alteração herdada". Por sua vez, os blocos da Figura 2 mostram fortes perdas de massa, claramente ocorridas já depois de ali terem sido colocados, que designaremos como "deterioração". A morfologia muito específica destas situações permite designálas como "arenização" e "descamação".

Em monumentos construídos com granito, podemos, pois, esperar encontrar todas as variações possíveis de qualidade dos materiais, desde as variedades mais sãs, resistentes e duráveis, até às variedades muito alteradas, que desembocam em processos de deterioração que podem chegar a ser drásticos e bastante rápidos.

\section{OS GRANITOS NO LABORATÓRIO. PERCEBER PARA CONCLUIR}

Em termos simples, os granitos utilizados nas construções exibem, como marcas mais relevantes da sua evolução através da crosta terrestre, uma fissuração mais ou menos densa e algumas marcas deixadas pelos processos de alteração, em particular a hidrólise dos feldspatos. Sendo devidos a episódios de rotura, as fissuras são superfícies mais ou menos planares, de espessura ínfima e grande desenvolvimento em área. Elas afectam fortemente as características mecânicas, como a resistência, e a sua presença e a sua aç̧ão são facilmente identificadas através da medição da velocidade de propagação de ultrassons (VL).
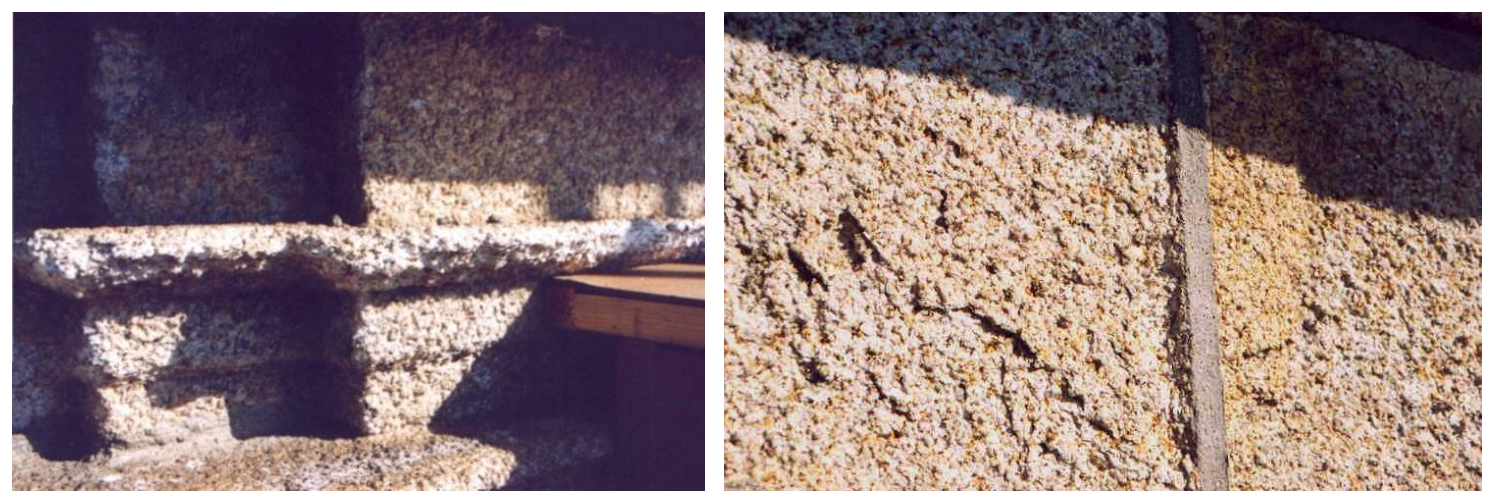

Figura 2. Exemplos de arenização em blocos de granito na igreja do Mosteiro de Tibães. Esta deterioração extrema demonstra uma alta taxa de alterabilidade, o que só pode ser explicado pela alteração adquirida durante a fase pré-extracção (alteração herdada). 
Por sua vez, a influência que têm no aumento da porosidade é mínima, pelo que uma rocha bastante fissurada, que tenha a velocidade de ultrassons reduzida a metade pode apresentar uma porosidade que não exceda os 2 a $3 \%$. As modificações devidas a hidrólise são mais influentes em termos de aumento de porosidade, mas a sua influência pode ser tão devastadora que, antes da porosidade ter chegado aos $5 \%$, já a rocha está fisicamente muito debilitada e a atingir os limites da sua utilidade como elemento de construção. Quer isto dizer que, em laboratório, para estudar rochas graníticas, implica ter em conta que estamos a lidar com materiais fissurados e numa gama de porosidades entre 1 e $5 \%$. Por comparação, nas rochas sedimentares, como os calcários e arenitos, os vazios são poros e não fissuras e as porosidades pode variar entre 1 e $50 \%$.

As linhas anteriores contêm os pressupostos básicos indispensáveis para delinear qualquer estratégia de abordagem dos problemas de deterioração e para estudar e decidir sobre estratégias de conservação, e que são: i) os granitos são rochas silicatadas, com fedspatos e quartzo como constituintes principais e determinantes; ii) a porosidade varia com o estado de alteração e em geral situa-se entre 1 e $5 \%$; iii) os vazios são, essencialmente, de tipo fissura, iv) a alteração herdada da fase pré-extracção é o factor mais determinante do comportamento deste tipo de materiais em obra.

Estes pressupostos devem estar sempre presentes na hora de abordar os problemas de deterioração e as acções de conservação. As caracterizações laboratoriais são indispensáveis para ajudar a obter respostas às questões em causa, mas é o contexto definido por aqueles pressupostos que permitirá extrair a informação mais relevante para chegar a essas respostas. Os parágrafos seguintes procuram apontar alguns percursos interpretativos nesta linha de pensamento.

As baixas porosidades poderiam levar a pensar que estas rochas têm fraca absorção ou que seriam quase impermeáveis. O facto de apresentarem fissuras determina outra realidade. Os granitos não absorvem muita água, de facto, mas absorvem-na muito velozmente. Em termos ilustrativos, podemos dizer que um calcário com $30 \%$ de porosidade absorve 10 vezes mais água do que um granito com $3 \%$, mas saturam-se mais ou menos ao mesmo tempo!

$\mathrm{Na}$ Figura 3, apresenta-se um gráfico muito conhecido, elaborado na década de 1970 (TOURENQ \& FOURMAINTRAUX, 1974), que mostra a evolução do índice de qualidade (calculado a partir da velocidade de propagação de ultrassons) com o aumento da porosidade, neste caso aplicado na caracterização de variedades de granitos portugueses. Nele se verifica que, nos calcários, o índice varia de forma suave à medida que aumenta a porosidade, enquanto que, nos granitos, a variação é abrupta, reduzindo-se fortemente com pequenos aumentos da porosidade.

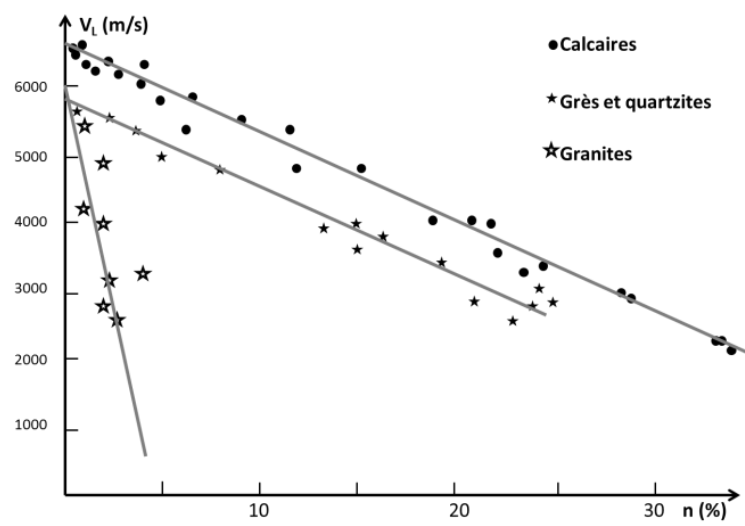

Figura 3. Relação entre a porosidade total ( $n$ ) e a velocidade de propagação das ondas $\left(V_{L}\right)$ nas rochas porosas (grés e calcários) $e$ nas rochas fissuradas (granitos), segundo Tourenq \&

Fourmaintraux, 1974 (gráfico redesenhado a partir do original).

As transformações químicas introduzidas pela hidrólise dos feldspatos consistem, basicamente, na entrada de iões $\mathrm{H}+$ que substituem iões $\mathrm{Na}+, \mathrm{K}+$ ou $\mathrm{Ca++}$ na estrutura cristalina. Com o avanço do processo, a estrutura cristalina fica debilitada e podem formar-se novos compostos, como os minerais das argilas, que tornam todo a estrutura mais débil e globalmente mais sensível em ambientes de exposição exterior. Em termos das características físicas, estas debilidades somam-se ao impacte já induzido pela fissuração, e na interpretação dos estudos laboratoriais, as duas componentes devem ser tidas na devida consideração.

Em contacto com água as rochas graníticas saturam-se rapidamente e secam com facilidade, e tanto mais quanto mais alteradas estiverem, e são especialmente sensíveis quando a água contém sais em solução. Em tais circunstâncias, as rochas graníticas podem sofrer taxas de deterioração muito elevadas.

Também os tratamentos de conservação devem ser entendidos e estudados à luz daqueles pressupostos. Assim, a composição silicatada configura compatibilidade química com produtos de tratamento como o silicato de etilo, os silanos e polissiloxanos, e a fácil absorção permite antever que o tratamento destes materiais será possível.

Com estes conhecimentos de base e observando os exemplos ilustrados nas Figuras 1 e 2, poderíamos deduzir algumas considerações, como por exemplo: a forte redução da velocidade de propagação de 
ultrassons mostra que existe uma acentuada fissuração; a desagregação granular é consequência da hidrólise que debilitou a matriz feldspática; os sais solúveis e as variações térmicas e higrométricas devem ser os mecanismos de deterioração responsáveis pelas acentuadas perdas de massa. Para contrapor à forte erosão pode ser necessário consolidar, podendo admitir-se que um silicato de etilo poderia ser considerado como solução potencialmente interessante e a comprovar.

\section{AS OBRAS COM OS SEUS PROBLEMAS E ENSINAMENTOS}

Os conhecimentos de base geológica são essenciais e o estudo laboratorial é uma via de extrema utilidade, mas saber olhar para a realidade e dela extrair ensinamentos e orientações é igualmente relevante.

$\mathrm{Na}$ figura 4 apresentam-se dois exemplos retirados de um monumento construído com blocos de granito sobrepostos sem qualquer argamassa de assentamento. Nos blocos centrais identificam-se marcas deixadas por furos usados para injecção profunda de resinas nesses mesmos blocos. Observando atentamente o que se passa nestes e nos blocos vizinhos percebe-se que a evolução se dá por erosão que avança dos cantos e arestas até conduzir ao completo arredondamento do bloco. Neste contexto, evitar a progressão do processo erosivo que conduz ao arredondamento deveria ser o objectivo da intervenção, pelo que a opção de injectar em profundidade deixando a erosão a actuar parece bastante discutível como solução. Discutível, pelo menos, foi também a opção de tratar aqueles blocos deixando outros sem tratamento, quando o seu estado de alteração e o grau de arredondamento mostram que a situação do material será igual ou pior do que a dos blocos tratados.

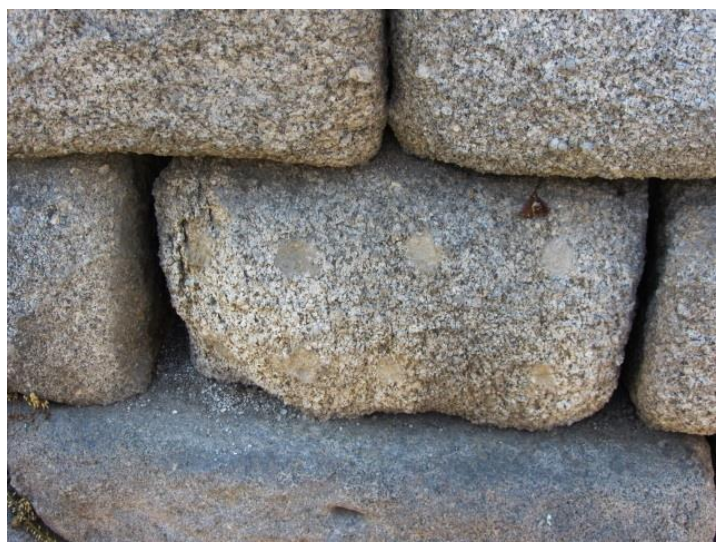

Para entender os problemas que aqui se desenrolam e abordar a situação é útil rever o modelo de evolução atrás enunciado. Estes blocos evoluíram na fase de pré-extracção e pela forma como se dá o avanço da alteração, não é concebível que os blocos estejam mais alterados no interior do que à superfície. A injecção profunda não tem, pois, justificação lógica. Por outro lado, a alteração em obra é fortemente influenciada pelos agentes exteriores, pelo que a arenização e descamação são de esperar que avancem de fora para dentro. Nesta lógica, o tratamento deveria acautelar a situação à superfície, procurando evitar a erosão e o risco que o seu avanço causa na segurança estrutural.

Como em todos os tipos de rochas, as construções em granito quando expostas adquirem os mais diversos tipos de sujidade, pelo que acções de limpeza terão em algum tempo de ser consideradas. Como foi apontado para o caso do tratamento, também quanto à limpeza há especificidades que devem ser tidas em conta. Desde logo, a sua composição silicatada diferencia os granitos de outros grandes grupos de materiais, como sejam os calcários e os mármores, no que diz respeito aos padrões de sujidade que exibem e quanto à eficácia e potencial nocividade dos métodos de limpeza. Nesta perspectiva, haverá semelhanças com as construções em arenitos, de composição silicatada como eles, mas de origem sedimentar.

Nas fachadas de edifícios de rochas carbonatadas é frequente ocorrerem padrões de sujidade com forte contraste entre zonas lavadas pela água das chuvas e zonas protegidas onde essa lavagem não chega. Nas fachadas construídas com rochas graníticas, os padrões de sujidade tendem a ser mais homogéneos, não ocorrendo os contrastes tão características das rochas carbonatadas. Na Figura 5 ilustram-se situações deste género.

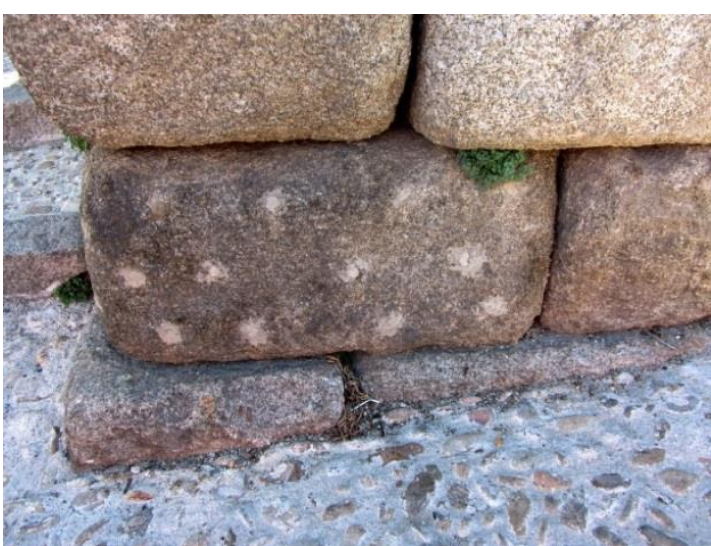

Figura 4. Blocos de granito com sinais de furos de injecção profunda para consolidação com resina epoxídica. A figura da esquerda mostra que a erosão continua e que a injecção não teve qualquer acção, como seria de esperar. A figura da direita mostra que o bloco tratado ainda estava longe do estado de alteração e do grau de arredondamento de muitos dos blocos não tratados, pelo que se podem levantar dúvidas sobre o critério usado na selecção dos blocos a tratar. Uma análise baseada nos pressupostos acima anunciados teria seguramente conduzido a outra solução de tratamento e a outro critério de selecção dos blocos a tratar. 


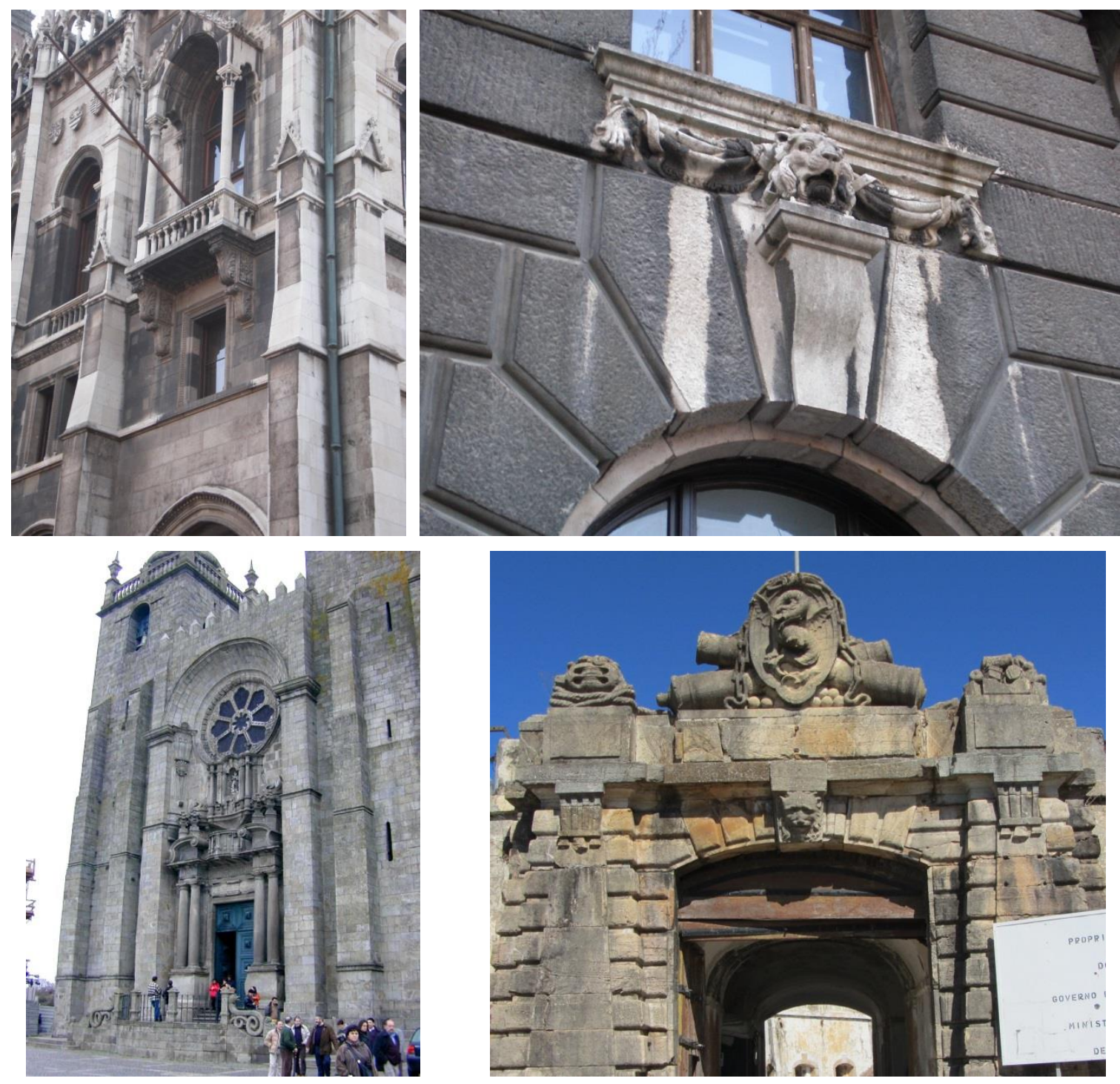

Figura 5. Padrões de sujdade típicos de fachadas em rochas carbonatadas (em cima) e de rochas silicatadas, como os granitos, (em baixo). As zonas "lavadas" são devidas a dissolução da matriz calcítica que, ao ser eliminada, leva consigo a sujidade. A grande insolubilidade dos silicatos impede que esse fenómeno se repita nos granitos.

$\mathrm{Na}$ de limpeza de fachadas carbonatadas, os métodos hídricos beneficiam da solubilidade da calcite, ainda que pequena, e tendem a ser por isso muito mais eficazes do que nos substratos silicatados. A transposição da experiência de um para outro grupo de materiais pode portanto ser arriscada e todas as extrapolações precipitadas devem pois ser evitadas.

Nas rochas silicatadas é frequente encontrar um tipo de sujidade muito aderente ao substrato, de cores sempre muito escuras e de extrema dificuldade de remoção. São os chamados "filmes negros", que ocorrem em áreas expostas e que sofrem molhagem, ao contrário das "crostas negras" que ocorrem sempre em zonas protegidas da lavagem pela chuva. Enquanto que as crostas negras sempre apresentam gesso, os filmes negros não contêm gesso e em geral apresentam assinaláveis teores em ferro.
A Figura 6 apresenta duas situações com filmes negros em fases distintas de desenvolvimento e duas fotos obtidas ao MEV de amostras de granito recobertas por filmes negros. A foto do canto superior esquerdo mostra uma clara associação de manchas esverdeadas devidas a colonização por algas com as ocorrências de filmes negros e as fotos ao MEV mostram que os filmes estão sempre muito aderentes ao substrato. $O$ paralelismo entre as ocorrências dos filmes negros e os nichos ecológicos de crescimento de colonização por algas, e a morfologia tão especial destes filmes vista ao MEV leva a admitir que estes filmes sejam um produto dessa mesma colonização (DE CASTRO, et al. 1988, DELGADO RODRIGUES et al. 2014)

A origem biológica destes filmes negros permite dizer que a cor muito escura será devida à produção de melanina, cuja extrema insolubilidade justifica a dificuldade que é reconhecida na eliminação deste tipo de depósitos. 

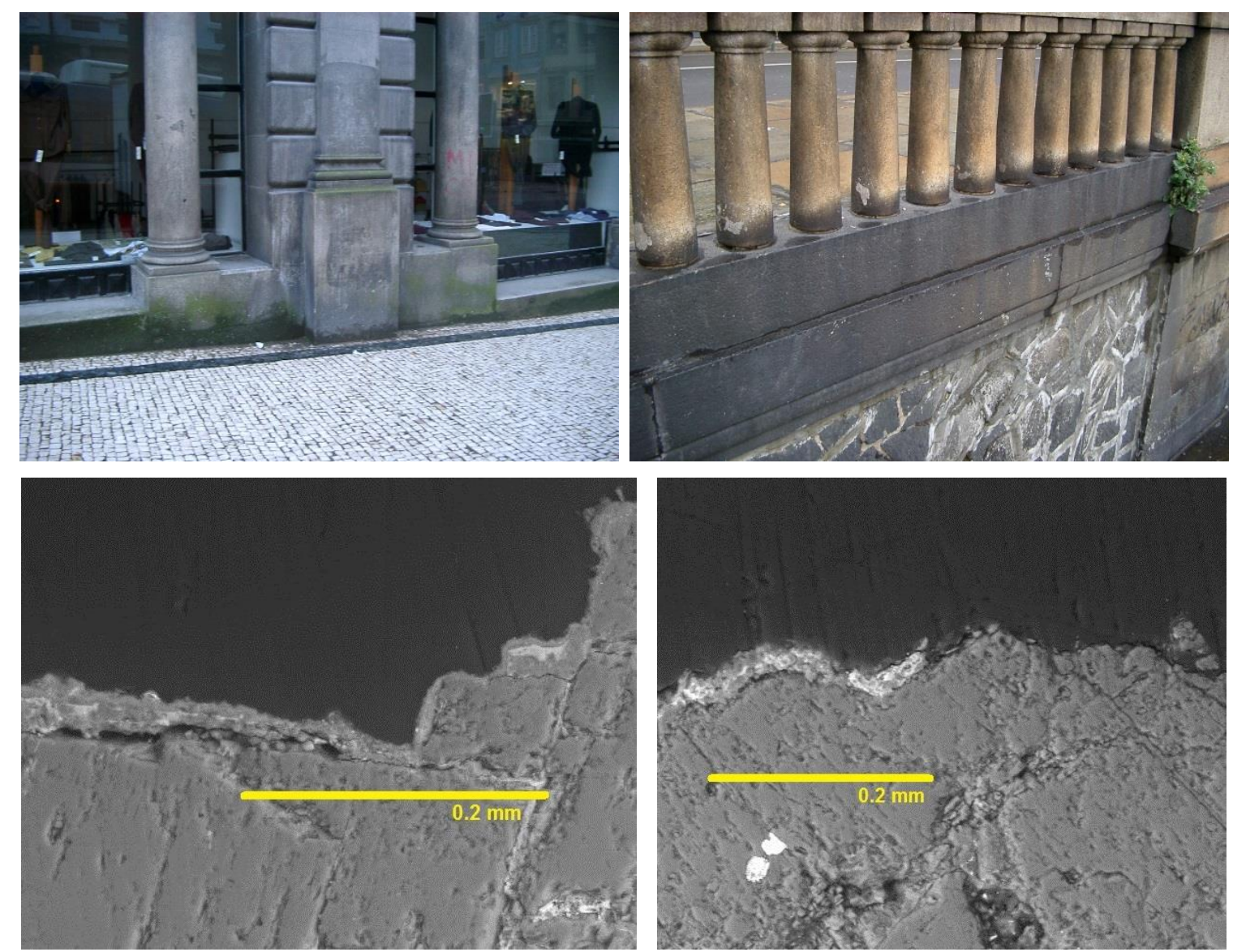

Figura 6. Aspecto de filmes negros (em cima) e imagens ao MEV de secções de granito recobertas de filmes negros. Note-se a estreita associação da colonização verde na foto em cima à esquerda e a morfologia do finíssima camada que se molda e adere fortemente ao substrato (em baixo). A imagem da direita foi obtida após ensaio de limpeza com Laser na transição entre a zona limpa e suja. Nos filmes

negros identificam-se finíssimas partículas brilhantes que são partículas de ferro retidas no biofilme. Imagens MEV com electrões retrodifundidos.

Em estudo recente (DELGADO RODRIGUES, et. al. 2014) testámos o uso da radiação laser para eliminação de filmes negros em substratos razoavelmente bem conservados. A presença de minerais escuros, como a biotite, torna os substratos graníticos muito sensíveis à radiação Laser, pelo que só para certas condições foi possível obter limites de nocividade admissíveis. A limpeza com radiação Laser é possível, mas as condições de operação são mais difíceis de encontrar do que nos substratos de cores claras e devem ser devidamente validadas, caso a caso.

Importa, ainda, salientar que os filmes negros não interferem com o substrato, como bem demonstram aos imagens ao $\mathrm{MEV}$, pelo que $\mathrm{o}$ problema de conservação que constituem se restringe ao efeito inestético que em geral provocam. Nesta linha, a sua remoção não é exigida por questões de melhor conservar o objecto, pelo que se pode encarar a sua atenuação e não procurar a remoção integral, moderando o efeito inestético, mas evitando possíveis danos que a remoção forçada poderia facilmente implicar.

\section{REFERÊNCIAS BIBLIOGRÁFICAS}

DE CASTRO, E., DELGADO RODRIGUES, J. and CRAVO, M.R.T. Étude du nettoyage d'un monument en granite. $\mathrm{VI}^{\text {th }}$ Int. Cong. on Deterioration and Conservation of Stone: Toruń, 1214.09.1988, pp. 766-774.

DELGADO RODRIGUES, J.; COSTA, D.; MASCALCHI, M.; OSTICIOLI, I. and SIANO, S. - Laser ablation of iron-rich black films from exposed granite surfaces. Appl. Phys. A, 117:365-370, 2014.

STRECKEISEN, A. - "To each plutonic rock its proper name". EarthSciences Review, vol. 12, No 1, 1976, pp. 1-33.

TOURENQ, C et FOURMAINTRAUX, D. - $L^{\prime}$ indice de qualité des roches. Quelques applications. Proc. $2^{\text {nd }}$ Int. Cong. IAEG, Sao Paulo, 1974. Paper IV-20.1.

Contribuição ao

1‥ Simpósio Brasileiro de Caracterização e Conservação da Pedra 14 a 16 de dezembro de 2016, Congonhas - MG

Nota:

É de responsabilidade da comissão editorial do Simpósio a revisão gramatical, ortográfica, de citações e referências bibliográficas. As normas de submissão podem se diferenciar das desta revista. 